\title{
Incomplete Contracts as a Screening Device in Competing Vertical Inter-Firm Relationships
}

\author{
Marta Sicoli and Marco Maria Sorge
}

\section{(2) OpenEdition \\ 1 Journals}

\section{Electronic version}

URL: https://journals.openedition.org/rei/5889

DOI: 10.4000/rei.5889

ISSN: 1773-0198

Publisher

De Boeck Supérieur

\section{Printed version}

Date of publication: 30 September 2014

Number of pages: 141-181

ISBN: 9782804190309

ISSN: 0154-3229

\section{Electronic reference}

Marta Sicoli and Marco Maria Sorge, "Incomplete Contracts as a Screening Device in Competing Vertical Inter-Firm Relationships", Revue d'économie industrielle [Online], 147 | 3e trimestre 2014, Online since 30 September 2016, connection on 07 June 2022. URL: http://journals.openedition.org/rei/5889 ; DOI: https://doi.org/10.4000/rei.5889 


\title{
INCOMPLETE CONTRACTS AS A SCREENING DEVICE IN COMPETING VERTICAL INTER-FIRM RELATIONSHIPS*
}

\author{
Marta Sicoli ${ }^{\dagger}$, F.I.E.L.D. Foundation, Regione Calabria \\ Marco M. Sorge $\ddagger$, University of Napoli Federico II and CSEF
}

Keywords: Vertically Integrated Firms; Asymmetric Information; Incomplete Contracts; Screening.

Mots-clés : Entreprises intégrées verticalement ; Asymétrie d'information ; Contrats incomplets ; Procédure de sélection.

\section{INTRODUCTION}

Over the last years, the applied contract theory literature has paid a great deal of attention to the analysis of the strategic value of contractual incompleteness for the optimal design of industry relationships. In particular, in contrast to existing models arguing in favor of vertical price restrictions as monitoring tools, several recent studies have shown that the exploitation of agreements which remain silent on some

\footnotetext{
We wish to thank Gianmaria Martini, Salvatore Piccolo, two anonymous reviewers and participants at the $53 \mathrm{rd}$ Annual Scientific Meeting of the Italian Society of Economists and the XXIV Conference of the Italian Society of Public Economics, for insightful comments and discussions. Any remaining errors are our own. The views of this paper are those of the authors and do not necessarily represent those of the institutions they are affiliated with.

$\dagger \quad$ E-mail: martasicoli@libero.it

$\ddagger \quad$ E-mail: marco.m.sorge@gmail.com
} 
(verifiable) relationship-specific measures can improve upon the complete contracting scenario by positively influencing the market performance of competing vertical hierarchies (e.g., Martimort and Piccolo, 20Io; Kastl et al., 20II) ${ }^{\text {. }}$.

The present paper aims at contributing to the analysis of the strategic value of incomplete contracts by focusing on their screening efficacy in a class of (competing) vertical inter-firm relationships, such as manufacturer-retailer ones, where contracting may suffer from both adverse selection and moral hazard issues. Our focus on this particular market structure is motivated by different sets of empirical findings. A first one is concerned with the highly incomplete nature of business contractual relationships within vertically related firms (e.g., Lafontaine and Slade, I997, 20Io). Different studies have also documented the relevance of demandenhancing activities of retailers (such as promotional expenditures) and their role in price determination in competitive settings (e.g., Chevalier et al., 2003), which creates room for moral hazard issues. The nature of contracts stipulated between vertically related firms is also arguably affected by several external factors - such as upstream competitive pressure, retailers' resource constraints, multi-market retailing activities - which ultimately shape retailers' incentives to participation in agency relationships. More generally, the existence of a direct correlation between retailers' performances and their outside opportunities can be regarded as a generic feature of vertical contracting in most circumstances of interest (e.g., Acconcia et al., 2008). Despite its potentially non-negligible impact on the design of optimal contracts, the interplay between the (endogenous) degree of contractual completeness and the screening role of alternative sets of rules governing the terms of trade have been largely neglected in the literature. This lack of interest might be due to the generic tenet that a (sufficiently) complete contract, which endows the producer with multiple instruments to control the downstream agent, is more likely to favor truthful revelation of private information and hence provide an efficient solution to the asymmetric information issue.

I In these studies, the term hierarchy is employed to label a vertical agency relationship in which a downstream agent has to deal with an independent upstream supplier. Notably, this terminology diverges from the dichotomous view of markets and hierarchically organized firms (e.g., Williamson, 1975). We stick to Martimort and Piccolo (20I0)'s terminology throughout our analysis. 
The analysis developed in this paper offers a simple argument against this conjecture when countervailing incentives matter in vertical contracting. Specifically, we establish that incomplete (less complete) contracts may arise as an equilibrium phenomenon in market structures characterized by (horizontal) externalities across downstream competitors. While affecting the principal's control over the agent's conduct, the endogenous choice of contractual regimes crucially alters the basic rent extraction-efficiency trade-off as it qualifies the interactions between alternative incentive schemes (and the associated agency costs) and the contract-induced optimal market behavior of retailers. Our main result is to show that the standard second-best contract which remains silent on retail prices always induces self-selection and hence fully separating outcomes, irrespective of the agent's actual misreporting incentives, whereas a more complete one may well fail in this respect.

The intuition behind this counterintuitive result is as follows. It is wellknown that the existence of a trade-off between efficiency and rent extraction in agency problems leads to distortions with respect to the first best equilibrium allocations (e.g., Holmstrom, I982; Baron and Besanko, I984; Laffont and Tirole, 1986; Caillaud and Hermalin, 2000). In the context of vertically related firms, the producer's decision to delegate a given task to an independent retailer is typically rationalized by the superior knowledge and expertise that the latter exhibits with respect to the peculiar features of the downstream market. On the other hand, however, the same elements, along with the existence of asymmetric information on the actual production structure of retailers, typically generates informational rents for the latter which must be accounted for within the delegation arrangement. The basic idea underlying the alleged superiority of complete contracts in this respect is that only detailed agreements, which are able to control for (almost) all the specific contingencies relevant to the transaction, allow the principal to curb agents' discretion and properly steer both behavior and revelation strategies. This presumption, however, has been invalidated by several studies showing that, when at least one of the relevant variables for the transaction cannot be explicitly accounted for - since not observable by both the parties involved and/or verifiable by a third one - in the contract, the adoption of complete arrangements does not offer an efficient solution to the problems arising from the asymmetric distribution of information (e.g., Holmstrom and Milgrom, 1992; Bernheim and Whinston, 1998). 
The same conclusion applies, a fortiori, when the agent (retailer) is acting in a (imperfectly) competitive market. In these circumstances, the employment of an inclusive agreement would adversely affect the ability of retailers to efficiently react to his competitor's decisions and, more generally, to possible changes in the market environment ${ }^{2}$. In this setting, the possibility to incur losses in terms of profits or market share(s) because of inefficient contractual impositions generates an incentive to falsely reveal private information with the aim of seizing the informational rent and (partially) narrowing the expected adverse outcome. When, by contrast, the agent enjoys greater discretion as granted by the contractual agreement and has a residual claim on the (net) profits from selling, the ability to engage properly in competitive behavior creates stronger incentives to truthful information disclosure. Under these circumstances, fewer (binding) incentive compatibility requirements will enter the second best contract and the resulting equilibrium allocation will be characterized by a weaker distortion with respect to the adoption of (more) complete contracts, which may rather fail to ensure self-selection.

The present paper addresses these issues within an agency framework which captures the relationship between a manufacturer (principal) which produces an intermediate good in an upstream market and a retailer (agent) that sells the same good in a downstream market where he competes with a vertically integrated structure. Retailers possess private knowledge about the uncertain downstream demand(s), which is payoff-relevant (adverse selection problem), while the agent in the hierarchy retains the right of engaging in unverifiable demand-enhancing activities (moral hazard problem). Optimal contracts are of two alternative forms, that differ with respect to the number of variables over which the principal holds direct and/or indirect control through contractual prescriptions. Under Quantity Fixing (QF), the manufacturer imposes the achievement of specific sales targets on his partner. As a consequence, the agent is left free to set the selling price in the retail market and can exert an optimal (payoff maximizing) level of effort. With Resale Price Maintenance (RPM) contracts, by contrast, the principal

2 In this respect, Rey and Tirole (I986) establish that, whenever the seller has superior information relative to the producer, imposing no price restriction for decision-making in the market for final goods can warrant the latter a larger surplus. 
also sets the price to be charged in the downstream market, and hence imposes an indirect constraint on the agent's discretion in terms of the effort choice.

We explore the strategic role of incomplete contracts as a screening device by contrasting the self-selection effects of the mentioned contractual regimes in the standard two-type paradigm with those emerging in a more realistic setting, where both the unobservable types face an incentive to misreport. The theoretical framework is modified by allowing for countervailing incentives that arise from type-specific participation constraints, which - in the same spirit of Acconcia et al. (2008) - are used to model external factors influencing vertical contracting. When the reservation utility of the high-demand type agent is sufficiently large, to ensure participation in the contract the principal may be forced to offer more attractive contractual terms, which could overturn the losses that the low-demand type incurs in the current relationship should he choose to falsely report his own type (countervailing incentives). Hence, both agents can in principle gain from falsely revealing their private information to the principal. As a main result we will show that, irrespective of whether countervailing incentives arise in the specific agency relationship, QF contracts always induce truthful revelation via the standard second-best contract, whereas RPM arrangements fail to do so under several model parameterizations. More specifically, when both agent types face misreporting incentives, only the QF mechanism is able to neutralize the high-demand ones via the strategic effect identified by Martimort and Piccolo (20I0), which does not arise under RPM. Remarkably, this result holds true even when designing complete contracts is not costly for the principal, i.e. even when the two contractual modes are ex-ante identical at the writing stage.

The remaining paper proceeds as follows. The next section surveys the theoretical contributions that have inspired the present analysis. Section 3 sets up the basic model, while section 4 revisits the equilibrium analysis performed in Martimort and Piccolo (20I0). Section 5 focuses on the countervailing incentives case. The strategic value of contractual incompleteness as a screening device is identified and discussed in section 6 . Section 7 offers concluding remarks. 


\section{REFERENCE LITERATURE}

This paper is primarily related to the extensive literature on incomplete contracting, a fairly diversified strand of research that has allowed to successfully explore significant organizational issues such as the distribution of authority and the financial structure of firms (Grossman and Hart, 1986; Hart and Moore, 1990, I999; Maskin and Tirole, I999, among others). Studies in this field generally depart from the standard principal-agent framework as a convincing theoretical foundation for contractual incompleteness, and often take contractual incompleteness as a characterizing assumption for exogenous reasons, such as bounded rationality (e.g., Williamson, 1975) or costly verifiability (e.g., Hart and Moore, 1999). Other works aim at explaining endogenous incomplete contracts as arising from their formal nature (Anderlini and Felli, 1994), from the costly description of the underlying environment and parties' behavior (e.g., Battigalli and Maggi, 2002) or from limited cognition (e.g., Tirole, 2009) ${ }^{3}$. In this respect, we remark that our use of the notion of incomplete contracts as ad hoc restrictions on the set of feasible agreements focuses on less than comprehensive contracts which are on purpose (i.e. for strategic reasons) designed to remain silent on a number of contractible features. Notably, in contrast to the mentioned literature, our goal is to figure out conditions (if any) under which incomplete contracts may emerge as an equilibrium phenomenon even when writing complete contracts is costless and feasible. That is, we deliberately omit to consider contracting costs to focus on the suitability of different contractual regimes which are then identical at the contracting stage - to serve as a screening device. While this approach is intimately concerned with the trade-off between contract flexibility and control over opportunistic behavior (e.g., Williamson, 1975), it offers new insight into the strategic role of incomplete contracts when framed into a non-isolated principal-agent context, where the choice of the contractual regime has non-negligible effects on downstream competitive behavior.

The main theoretical reference of the paper is hence represented by the recent literature on the strategic value of incomplete contracts in specific

3 Other references that analyze incomplete contracts arising in hold-up problems are Che and Hausch (1999), De Fraja (I999), Che (2000), Segal and Whinston (2002), Fares (2006). 
agency relationships. Starting with Spengler (I950) and Telser (I960), studies on contracting in vertical inter-firm relations have investigated the deep connections between the existence of vertical restraints and the welfare properties of agreements between independent actors. The conclusions reached by scholarly work in the area over the years are far from being unambiguous. Contributions showing that any type of restrictions imposed on downstream firms have the detrimental effect of hindering competition and creating substantial welfare losses, have been challenged by studies emphasizing the potential for beneficial effects of vertical restraints for both the contractual parties and the consumers of final goods 4 . On a different account, several recent contributions have focused on the relationship between vertical restrictions and the degree of the informational problem which characterizes the relationship. Within the context of successive monopolies, Gal-Or (I99I) shows that the provision of contractual constraints on price - relative to the standard unconstrained scenario - reduces the dimensionality of the adverse selection problem and help to improve production efficiency as well as consumer welfare.

New interesting results have been obtained in this area by considering the possibility of moral hazard. Martimort and Piccolo (2007) compare the (private and social) effects of the usage of contracts with varying degrees of completeness, and find that, although the manufacturer always prefers a more complete agreement, the effect of price restrictions on consumers welfare is ambiguous and depends on how the choice of contractual arrangements - via its effect on the agent's effort decisions influences the willingness to pay for end users. Kastl et al. (20II) complement these findings by challenging the view that vertical price control proves beneficial to consumers as it generates lower input supply distortions. In contrast with the predictions of the standard theory of optimal contracting, according to which only a contingent agreement is able to replicate the first-best outcome, these contributions emphasize the existence of the counteracting role of contractual incompleteness in providing the principal with crucial strategic advantages that might overcompensate him for any inefficiencies related to lower degrees of control over their partners.

4 A widespread argument in this regard is that price restrictions prevent the phenomenon of double marginalization which is typical of successive monopolies, and can therefore improve the production efficiency of the transaction. 
The idea that the principal can take advantage of contractual incompleteness to influence the agent's conduct has received attention since the seminal contribution of Holmstrom and Milgrom (1992), who show that, in the presence of non-observability and/or non-verifiability of some of the relevant variables for the transaction, a greater degree of incompleteness may lessen the agent's incentive toward distorting his choices in favor of measurable aspects of performance and at the expense of the more important but not directly monitorable ones. In the same vein, Bernheim and Whinston (1998) argue that contractual incompleteness can lead to the adoption of more efficient choices because it promotes the functioning of the implicit component of the agreement and encourages cooperative behavior by both parties.

Also the existing scholarly work on the linkage between the degree of contractual completeness and the disclosure of private information differ from the present one in several respects. This strand of literature provides an informational rationale for the use of incomplete contracts as the latter allow to sensibly reduce the opportunities of renegotiation of the original agreement, hence influencing positively the revelation strategies as well as the investment choices of parties (Dewatripont and Maskin, I990, 1995). At the same time, contractual incompleteness minimizes the likelihood of sending an informative signal to others on the relevant features of the transaction and of the market in which the same takes place (Dessì, 2007). The basic idea behind these studies is that the amount of information which is (directly or indirectly) disclosed with the execution of the contract increases as the degree of contractual completeness deepens. The findings of this paper point exactly to the opposite direction, as they suggest that the use of less detailed contracts may foster the dissemination of new information in both direct (by encouraging the agent to truthfully report his private information), and indirect (by allowing ex-post deduction of new information on the agent via simple inspection of performance) ways.

The informative value of contractual incompleteness is underlined also by Allen and Gale (1992) and Spier (1992) in signaling models. In this context, a higher level of completeness can be interpreted by the agent as a signal of the principal's willingness to shield himself from potentially adverse scenarios by sharing the risk with his partner, while incomplete contracts 
may rather signal the willingness to bear any risk, which could be interpreted as a relatively low likelihood of negative events. In this paper, a screening model is considered, in which the designer of the contract is the uninformed party, and contractual incompleteness is exploited to induce truthful revelation of the agent's private information, by relying on the need for efficient competition on the downstream market.

The model's predictions also differ significantly from those of Allen and Gale (1992), in which the use of contracts with missing contingencies as a signaling mechanism necessarily causes pooling-type equilibrium outcomes, and hence prevents the agent from inferring the principal's information. Our analysis, by contrast, shows that less binding agreements are able to guarantee the separation of unobservable types at equilibrium.

Another key difference lies in the channels through which contractual incompleteness influences the nature of equilibria. In Spier (1992), the degree of completeness configures a relevant constituent of agreements only for intermediate levels of transaction costs, since for extreme levels the trade-off between risk sharing and type reporting is addressed by the principal by means of different instruments. In our model, the informational value of incomplete contracts becomes relevant depending on the agent's effort cost, as well as on the (private versus cooperative) nature of the latter and the existing relationship between the goods sold in the downstream market.

Finally, our paper obviously refers to the countervailing incentives literature (e.g., Lewis and Sappington, 1989), more precisely to studies supporting the idea that countervailing incentives are not (per se) sufficient to determine the nature of equilibrium outcomes (e.g., Fudenberg and Tirole, I99I; Maggi and Rodriguez-Clare, 1995). In this respect, our paper shows that an important factor for the properties of equilibrium outcomes is the degree of contractual (in)completeness. This connection had already been analyzed by Acconcia et al. (2008) in a sequential monopolies environment with a continuum of types. Focusing on the impact of the chosen contractual regime on joint profits, the authors show that the use of less binding contracts can generate pooling equilibria because giving up on a monitoring instrument prevents the determination of type-dependent allocations for moderate types; in this case, the upward distortion of 
equilibrium allocations can entail an overproduction effect that mitigates the double marginalization problem. Our contribution differs from the latter on both the modeling side and the focus of analysis. First, as argued in the introduction, we explicitly consider (imperfectly) competitive markets, in which a market-related effect of contractual incompleteness arises. Second, since the core of this paper is represented by the screening performance of alternative contractual arrangements, we do not make any assumptions on the nature of contractual choice (cooperative versus noncooperative) and do not elaborate on neither (joint) profit nor consumers welfare issues. Consequently, it delivers strikingly different results in terms of the ability of constrained mechanisms such as QF to support fully separating equilibrium outcomes.

\section{THE MODEL}

The theoretical framework used in this paper is a two-type version of the model studied by Martimort and Piccolo (20I0). Our benchmark results those emerging under complete information and asymmetric information without countervailing incentives - reproduce those of Martimort and Piccolo (20I0), once adapted to the discrete case. For the sake of completeness, these findings are collected and discussed in section (4).

Our analysis departs from that of Martimort and Piccolo (20I0) in two main respects: first, while these authors mainly focus on the standard asymmetric information case with type-independent outside options, we explicitly consider the case of countervailing incentives, which are likely to arise in vertical contracting; second, given our focus on the screening role of endogenous contracts, we emphasize the relation existing between the choice of the contractual regime and the nature of the underlying equilibrium outcome.

\subsection{Basic setting and assumptions}

We consider a simple retail industry consisting of two retailers $R_{i}, i=1,2$, each of which produces a final output using an essential raw input provided by exclusive upstream suppliers $S_{i}, i=1,2$. The output is to be sold in the downstream market where the retailers compete on quantities 
(Cournot competition) using constant marginal costs technologies, for simplicity normalized to zero. While $R_{1}$ buys the input from an independent supplier $S_{1}$ upon payment of a transfer determined by the latter, $R_{2}$ is vertically integrated with her exclusive supplier $S_{2}$ and both produce as a single entity. As in Martimort and Piccolo (20I0), we label the vertical (nonintegrated) agency relationship $R_{1}-S_{1}$ as the hierarchy while the $R_{2}-S_{2}$ relationship will be simply referred to as the vertically integrated structure.

The election of this particular setting can be motivated as follows. On the one hand, introducing a one-sided manufacturer-retailer hierarchy enables to easily identify the effects of the asymmetric distribution of information on the design of the optimal delegation mechanism, and to point out the trade-off between control and efficiency faced by the principal when determining the optimal degree of completeness of the contract. On the other hand, since our focus is on the role of downstream market competition for the design of contracts, the comparison with a vertically integrated structure rather than a competing agency relationship offers the twofold advantage of sensibly simplifying the analysis and allowing to quantify the impact of the contractual problem on the equilibrium allocation, which in turn can be consistently contrasted with the benchmark cases of complete and asymmetric information without countervailing incentives. In fact, as our analysis will make clear, within this setting the distortion with respect to the first best allocation hinges on the onesided agency relationship, as the integrated structure is not plagued by asymmetric information problems and the competitor's best-response is independent of alternative assumptions about the distribution of information within the vertical relationship or about the contractual arrangement chosen by the principal $S_{1}$.

The system of (linear) inverse demand functions is given by:

$$
p_{1}\left(\theta, e, q_{1}, q_{2}\right)=\theta+e(\theta)-q_{1}(\theta)+\rho q_{2}(\theta),
$$

and

$$
p_{2}\left(\theta, e, q_{2}, q_{1}\right)=\theta+\sigma e(\theta)-q_{2}(\theta)+\rho q_{1}(\theta),
$$

where:

- $p_{i}$ denotes the retail price level charged for product $i$ in the downstream market, with $i=1,2$; 
- $\theta$ is a common shock to demands, whose realization is private information of retailers at the time contracts are signed. We assume $\theta \in \Theta:=\{\underline{\theta}, \bar{\theta}\}, 0<\underline{\theta}<\bar{\theta}<\infty$ and $\Delta \theta:=\bar{\theta}-\underline{\theta}$. With no loss of generality, both states are supposed equally likely;

- $e$ captures an unverifiable activity (effort) performed by the agent $R_{1}$ to influence the demand for final goods ${ }^{5}$. This variable captures a series of nonmarket activities - e.g., investment in advertising that may affect the outcome of competition both directly, by acting on willingness to pay of consumers, and indirectly, by influencing the market performance of the competitor. We assume that the level of $e$ is observable by neither $S_{1}$ (the principal) nor the competitor (the integrated structure), and that exerting a nonzero level of effort generates disutility $i(e(\theta))=\frac{\psi e^{2}(\theta)}{2}, \psi>0$.

- $\sigma$ is a parameter that captures the external effects of the agent's effort on the demand faced by the competitor (e.g., Che and Hausch, 1999). If $\sigma>0$, the effort displays a cooperative value and therefore influences positively the competitor's demand of goods; if $\sigma<0$, by contrast, the effort adversely affects the competitor's demand, while no effect arises when $\sigma=0$. To guarantee that own-effort effects exceed cross ones in the competitor's demand (2), we assume that $|\sigma| \leq 1$;

- $\rho$ is a parameter that measures the degree of product differentiation: $\rho>0$ means that the goods are complements, whereas $\rho<0$ defines substitutes. Under $\rho=0$, the goods are in no relationship with each other and the two sellers operate as monopolists. Again, to ensure that own-price effects are larger than cross ones, the restriction $|\rho| \leq 1$ is imposed.

For ease of exposition, given the two-type nature of the agency model, we will refer to the realized state of nature $\theta \in \Theta$ as the agent's low-demand $\underline{\theta}$ or high-demand $(\bar{\theta})$ type.

5 Since $S_{2}$ and $R_{2}$ are integrated, with no loss of insight it is assumed that the latter does not exert any type of effort, as in Martimort and Piccolo (2010). 


\subsection{Incentive mechanisms within the hierarchy}

We assume that the principal has two alternative contractual arrangements available to set up the vertical relationship. We adopt Martimort and Piccolo (2010)'s convention of referring to a restricted mechanism as a Quantity Fixing contract, and to an unrestricted one as a Resale Price Maintenance contract. Under QF, the producer designs a menu of contracts of the form $\left\{q_{1}(\hat{\theta}), t_{1}(\hat{\theta})\right\}_{\hat{\theta} \in \Theta}$, where $q_{1}$ represents the quantity to be sold and $t_{1}$ denotes the transfer requested for the furniture of the intermediate good, both contingent on the agent's report about the realization of demand $\hat{\theta}$. Under RPM, the principal offers a menu of contracts of the form $\left\{q_{1}(\hat{\theta}), p_{1}(\hat{\theta}), t_{1}(\hat{\theta})\right\}_{\hat{\theta} \in \Theta}$, where $p_{1}(\hat{\theta})$ is the price to be charged in the downstream market as a function of the agent's report about the realization of demand. We assume that both the principal and the agent are risk-neutral, and that the former can credibly commit himself not to renegotiate the contract offer after the effort choice has been undertaken.

A QF contract is less complete relative to RPM because it limits the set of screening instruments available to the upstream supplier as it remains silent on the retail price. In contrast, the RPM arrangement endows the principal with a twofold instrument to monitor the level of effort exerted by the agent ${ }^{6}$. Although more sophisticated, an RPM contract cannot be regarded as a complete agreement; as emphasized by Martimort (1996), every (secret) contract between the producer and the retailer is necessarily incomplete because, while specifying the tasks of the agent, the competitor's choices cannot be contracted upon?

6 Since under an RPM arrangement both the retail price and the quantity sold to the retailer are dictated, the upstream supplier has direct control on the retailer's effort level.

7 The model considers secret contracts: only the choice of the contractual regime is publicly announced (or verifiable by the competitor), while the specific terms of the agreement are known to the contractual parties only. Again following Martimort (1996), a version of the revelation principle can be invoked to restrict attention to direct and truthful mechanisms in order to characterize pure strategy Nash equilibria. 


\subsection{Timing}

Once the contractual regime is chosen and announced, the timing of the principal-agent model is as follows:

- $t=0$ : the state of demand $\theta \in \Theta$ is realized and observed only by the agent and the integrated structure;

- $t=1$ : the principal offers a menu of contracts on a take-it-or-leaveit basis, which belong to the elected class (QF or RPM);

- $t=2$ : the agent either rejects or accepts the offer. In the former case, the seller obtains his reservation utility and the integrated structure operates as a monopolist on the market. In the latter case, the agent selects a specific item out of the menu contingent on the report $\hat{\theta}$; then, the optimal level of effort is exerted, retail market (Cournot) competition takes place and payments are made upon observation of selling performances.

\section{BENCHMARK}

This intermediate section reviews general results from Martimort and Piccolo (20I0), which will be next used as a benchmark for our analysis of optimal contracting under countervailing incentives.

\subsection{Complete information}

When the demand parameter $\theta$ is common knowledge, the agent enjoys no informational advantage irrespective of the actual contractual mode. Hence, first-best allocations will be type-dependent and yield the efficient outcome of vertical integration. For ease of exposition, we let the superscript $j$ denote the $\mathrm{QF}(\mathrm{j}=\mathrm{Q})$ or the RPM $(\mathrm{j}=\mathrm{R})$ contractual regime, respectively.

\section{The vertically integrated structure.}

With zero marginal production costs, the profits of the vertically integrated structure are simply given by the market revenues. For any pair $\left\{e(\theta), q_{1}(\theta)\right\}_{\theta \in \Theta}$ implemented by the competitor, the integrated structure solves the program: 


$$
P_{2}: \max _{q_{2}(\theta)}\left[\left(\theta+\sigma e(\theta)-q_{2}(\theta)+\rho q_{1}(\theta)\right) q_{2}(\theta)\right]
$$

which yields, contingent on the realization of $\theta \in \Theta$, the following reaction function:

$$
q_{2}(\theta)=\frac{\theta+\sigma e(\theta)+\rho q_{1}(\theta)}{2} .
$$

The cross-effects of the effort exerted by the agent in the hierarchy and the quantity sold by the latter on the demand are captured by the signs of the parameters $\sigma$ and $\rho$. Remarkably, the choice of the contractual arrangement within the hierarchy has no impact on the reaction function of the integrated structure, which can then be exploited to derive the equilibrium levels of quantity and effort both under QF and RPM contracts.

\section{The hierarchy.}

The producer seeks to maximize his profit, given by the transfer from the seller, under the latter's participation constraint (PC). The constant (typeindependent) reservation utility is normalized to zero.

The agent's expected utility is represented by the revenues from selling in the downstream market net of the costs incurred to carry out the extra-production activities and to purchase the intermediate input in the upstream market. Specifically:

$$
U(\theta)=p_{1}(\theta) q_{1}(\theta)-\Psi(e(\theta))-t(\theta)
$$

while the seller's PC is given by:

$$
P C: \quad U(\theta) \geq 0 \text {. }
$$

Under either of the contractual arrangements, the principal is faced with the following program:

$$
P_{1}: \max _{e(\theta) q_{1}(\theta)} t(\theta)
$$

s.t. $\quad$ PC. 


\section{Quantity fixing.}

Using (I) in (4), the agent's utility can be written as:

$$
U(\theta)=\left[\left(\theta+e(\theta)-q_{1}(\theta)+\rho q_{2}(\theta)\right) q_{1}(\theta)-\Psi(e(\theta))-t(\theta)\right],
$$

from which the following first and second-order conditions on the optimal level of effort are obtained:

and

$$
e(\theta)=\frac{q_{1}(\theta)}{\psi}
$$

$$
\psi>\frac{1}{2}
$$

Making use of (5), the designed transfer can be expressed as a function of the agent's expected utility to yield:

$$
\begin{gathered}
P_{1}^{Q}: \max _{q_{1}(\theta)}\left[\left(\theta+e(\theta)-q_{1}(\theta)+\rho q_{2}(\theta)\right) q_{1}(\theta)-\Psi(e(\theta))-U(\theta)\right] \\
\text { s.t. } \mathrm{U}(\theta) \geq 0,
\end{gathered}
$$

and, for any realization of $\theta \in \Theta$, the reaction function is given by:

$$
q_{1}(\theta)=\frac{\theta+e(\theta)+\rho q_{2}(\theta)}{2} .
$$

Apparently, the quantity sold in the downstream market is a function of the demand parameter, as well as of the effort exerted by the agent and the quantity offered by the competitor, whose effects are governed by the existing relationship between the two final goods.

\section{Resale price maintenance.}

When the selling price in the downstream market is controlled by the principal via the RPM contract, the optimal effort level can be readily obtained from the inverse demand function (I):

$$
e(\theta)=p_{1}(\theta)+q_{1}(\theta)-\rho q_{2}(\theta)-\theta
$$


while the agent's utility can be expressed by integrating (I) and (9) into (4):

$$
U(\theta)=\left[p_{1}(\theta) q_{1}(\theta)-\Psi\left(p_{1}(\theta)+q_{1}(\theta)-\rho q_{2}(\theta)-\theta\right)-t(\theta)\right]
$$

The first-order conditions with respect to price and quantity are given by, respectively ${ }^{8}$ :

$$
q_{1}(\theta)=\Psi^{\prime}(e(\theta))
$$

and

$$
p_{1}(\theta)=\Psi^{\prime}(e(\theta))
$$

from which we obtain:

$$
q_{1}(\theta)=p_{1}(\theta)=\psi e(\theta) .
$$

The principal's optimization program can be then recast in the following form:

$$
\begin{gathered}
P_{1}^{R}: \max _{q_{1}(\theta), p_{1}(\theta)}\left[p_{1}(\theta) q_{1}(\theta)-\Psi\left(p_{1}(\theta)+q_{1}(\theta)-\rho q_{2}(\theta)-\theta\right)-U(\theta)\right] \\
\text { s.t. } \mathrm{U}(\theta) \geq 0 .
\end{gathered}
$$

Then for any $\theta \in \Theta$, the equilibrium allocation under $Q F$ contracts is obtained using the reaction functions of the two competitors (3)-(8) and the first-order condition on the effort (6), while in the case of RPM contracts it is obtained using (3) and the first-order conditions for price and quantity (II). We then have

Proposition I. Under complete information, the equilibrium allocation is not affected by the chosen contractual mode, i.e.:

$$
\begin{gathered}
q_{1}^{j}(\theta)=\psi \frac{\theta(2+\rho)}{\left(4 \psi-\psi \rho^{2}-\rho \sigma-2\right)}, \quad \theta \in \Theta, \quad j=Q, R \\
e_{1}^{j}(\theta)=q_{1}^{j}(\theta) / \psi, \quad \theta \in \Theta, \quad j=Q, R \\
q_{2}^{j}(\theta)=\frac{\theta(2 \psi+\psi \rho+\sigma-1)}{\left(4 \psi-\psi \rho^{2}-\rho \sigma-2\right)}, \quad \theta \in \Theta, \quad j=Q, R
\end{gathered}
$$

8 The second-order condition is the same as under QF, see (7). 
In words, under complete information no vertical externality arises within the hierarchy, and the agent's effort choice is always aligned with that of the vertical hierarchy formed with his own principal. This holds true irrespective of whether the downstream retailer is left free to optimally choose his own level of effort (under QF), or rather is constrained through a price-fixing contract (under RPM). Hence, no loss of efficiency arises from keeping the contract silent with respect to the price instrument.

\subsection{Asymmetric information}

The asymmetric distribution of information introduce a vertical externality between the producer and the retailer, as the latter tries to exploit to their own benefit the informational advantage (superior information on downstream market conditions) by implementing opportunistic behavior that might affect both revelation strategies and effort choices. As shown in Martimort and Piccolo (2010), the agency problem cannot be solved by resorting to more sophisticated RPM contracts because vertical price restraints are not, per se, sufficient to disentangle the effect of the (exogenous and unobserved) demand shock from the effect of (endogenous and unobserved/unverifiable) effort choice of the agent on the actual market demand. Put simply, RPM arrangements do not allow the principal to fully extract the informational rent from the agent in order to fill the gap that characterizes the vertical relationship. However the particular choice of the contractual arrangement might still have a role in shaping the magnitude of the equilibrium distortion induced by information asymmetries, and therefore the characterization of final allocations. With (imperfectly) competitive markets, the principal can voluntarily give up on one (or more) control tools in order to take advantage of the horizontal externalities existing at the downstream level (captured by the parameters $\rho$ and $\sigma$ ). In particular, when the agent is left free to set up their optimal level of effort, he would be able to respond more efficiently to competition and hence affect the market behavior of the competing structure. Conditional on the existence of effort spillovers and some degree of differentiability between the goods, this in turn may drive the integrated structure to behave in a more friendly manner at the market stage, and overcompensate the agency cost effect arising from the foregone price control. 


\section{The vertically integrated structure.}

Since the uncertainty on the realization of the demand generates no incentive to deviate, the reaction function is not modified with respect to the complete information case (equation 3), and the distortions in the equilibrium demand depend exclusively on the cross-effects from the competitor's behavior and effort choices over the allocation of market shares.

\section{The hierarchy.}

Under asymmetric information, the principal is faced with the following optimization program:

$$
\begin{aligned}
P_{1} & : \max _{t} \frac{1}{2} t(\bar{\theta})+\frac{1}{2} t(\underline{\theta}) \\
\text { s.t. } P C & : U(\theta) \geq 0 \\
I C & : U(\theta) \geq U(\tilde{\theta} \mid \theta),
\end{aligned}
$$

where $U(\tilde{\theta} \mid \theta)$ indicates the $\theta$-type agent's utility from entering the contract and falsely reporting $\tilde{\theta} \neq \theta$. Remarkably, under this standard version of the problem, only the high-demand agent has an incentive to misreport his type, so as to take advantage of the resulting lower costs of effort: the relevant constraints for the optimal contracting problem under asymmetric information are then represented by the $\bar{\theta}$-agent's incentive constraint and the $\underline{\theta}$-agent's participation constraint, which must be binding at the optimum ${ }^{9}$. Appendixes A and B report the derivation of the IC constraints of the $\theta$-type agent in the presence of QF and RPM contracts, respectively.

\section{Quantity fixing.}

As the agent observes the demand parameter, his utility is still given by (5) and the following first- and second-order conditions on the optimal level of effort obtain:

and

$$
e(\theta)=\frac{q_{1}(\theta)}{\psi}
$$

$$
\psi>\frac{1}{2}
$$

9 This is a standard argument from the theory of incentives (e.g., Laffont and Martimort, 2002). 
Using the agent's informational rent to pin down the level of the transfer and the IC constraint of the high-demand type, the principal's problem is (see Appendix C):

$$
\begin{gathered}
P_{1}^{Q}: \max _{q_{1}} \frac{1}{2}\left[\left(\bar{\theta}+e(\bar{\theta})-q_{1}(\bar{\theta})+\rho q_{2}(\bar{\theta})\right) q_{1}(\bar{\theta})-\Psi(e(\bar{\theta}))-q_{1}(\underline{\theta})\left(\Delta \theta+\rho \Delta q_{2}(\theta)\right)\right]+ \\
\frac{1}{2}\left[\left(\underline{\theta}+e(\underline{\theta})-q_{1}(\underline{\theta})+\rho q_{2}(\underline{\theta})\right) q_{1}(\underline{\theta})-\Psi(e(\underline{\theta}))\right] .
\end{gathered}
$$

where $\Delta q_{2}(\theta):=q_{2}(\bar{\theta})-q_{2}(\underline{\theta})$.

The reaction functions are:

$$
q_{1}(\bar{\theta})=\frac{\bar{\theta}+e(\bar{\theta})+\rho q_{2}(\bar{\theta})}{2}
$$

and

$$
q_{1}(\underline{\theta})=\frac{\underline{\theta}+e(\underline{\theta})+\rho q_{2}(\underline{\theta})}{2}-\frac{\left(\Delta \theta+\rho \Delta q_{2}(\theta)\right)}{2} .
$$

Apparently, the quantity sold in the downstream market is a function of the demand parameter, as well as of the effort exerted by the agent and the quantity offered by the competitor, whose effects are governed by the existing relationship between the two final goods.

While the optimal choice of effort is unaltered with respect to the complete information scenario, the principal is forced to introduce a distortion in the production level assigned to the low-type agent $\underline{\theta}$ to weaken the informational rent obtained by the high-demand type $\bar{\theta}$ when he misreports his private information. The magnitude and the sign of this distortion depend on both the extent of the asymmetric information problem and the production decisions of the vertically integrated structure in any possible state of demand. This alteration, in turn, rebounds both on the competitor's market share (via the cross effect of $\rho$ and $\sigma$ ) and on the effort choice of the low-demand agent, since the optimally chosen level of effort is a linear function of quantity ${ }^{\mathrm{IO}}$. Hence, the information rent does not depend exclusively on the level of production requested from the latter, and the sign of the distortion need not be negative for any parameter-

IO Appendix E reports the equilibrium allocation under QF contracts. 
ization of the model. This finding is clearly affected by the assumption of competitive downstream market and by the interaction between adverse selection and moral hazard. The following Lemma clarifies the circumstances under which, at the second best optimum, the menu of contracts involves a downturn output distortion for the low-type agent:

Lemma r. Let $q_{1}^{Q}(\theta), \theta \in \Theta$ be the output allocation under the QF contract. Then:

$$
q_{1}(\bar{\theta})>q_{1}(\underline{\theta}) \Leftrightarrow \Delta \theta+\rho \Delta q_{2}(\theta)>0
$$

Proof. - See Appendix E.

A direct implication of Lemma I is the monotonicity of the second-best schedule of outputs under the reported condition ${ }^{\mathrm{II}}$.

\section{Resale Price Maintenance.}

As the agent (retailer) acts as the informed player, equation (Io) can be readily exploited to derive the first-order conditions with respect to price and quantity ${ }^{12}$ :

and

$$
q_{1}(\theta)=\Psi^{\prime}(e(\theta))
$$

$$
p_{1}(\theta)=\Psi^{\prime}(e(\theta))
$$

from which we obtain:

$$
q_{1}(\theta)=p_{1}(\theta)=\psi e(\theta) .
$$

The principal's optimization program can be written as (see Appendix D):

$$
\begin{aligned}
& P_{1}^{R}: \max _{q_{1}, e} \frac{1}{2}\left[\left(\bar{\theta}+e(\bar{\theta})-q_{1}(\bar{\theta})+\rho q_{2}(\bar{\theta})\right) q_{1}(\bar{\theta})-\Psi(e(\bar{\theta}))-[\Psi(e(\underline{\theta}))-\Psi(e(\underline{\theta})-\right. \\
& \left.\left.\left(\Delta \theta+\rho \Delta q_{2}(\underline{\theta})\right)\right)\right]+\frac{1}{2}\left[\left(\underline{\theta}+e(\underline{\theta})-q_{1}(\underline{\theta})+\rho q_{2}(\underline{\theta})\right) q_{1}(\underline{\theta})-\Psi(e(\underline{\theta}))\right] .
\end{aligned}
$$

II However, as it will be made clear in the following, the monotonicity requirement is not necessary for the omitted IC constraint to be satisfied at the second best optimum. See Appendix I.

I2 The second-order condition is the same as under QF, see (13). 
and first-order conditions with respect to effort and quantity are:

and

$$
q_{1}(\theta)=\frac{\theta+e(\theta)+\rho q_{2}(\theta)}{2}, \quad \theta \in \Theta
$$

$$
\begin{gathered}
e(\bar{\theta})=\frac{q_{1}(\bar{\theta})}{\psi}, \\
e(\underline{\theta})=\frac{q_{1}(\underline{\theta})}{\psi}-\frac{\left(\Delta \theta+\rho \Delta q_{2}(\theta)\right)}{\psi} .
\end{gathered}
$$

Under RPM contracts, the downstream agent faces a retail price target, and is then forced to choose a suboptimal effort level from his viewpoint. A nonzero information rent engenders a distortion in the level of effort - and not in the quantity to be produced - of the agent who faces a low state of demand. Again, the actual sign of the effort distortion relies on the uncertainty about the realization of demand and the cross-effect of such uncertainty on the quantity sold by the vertically integrated structure. In equilibrium, the optimal effort decision will influence the output produced by the low-demand type, whereas the optimal effort exerted by the high-demand type as well as his output level will attain their first best levels ${ }^{\mathrm{r}}$.

Intuitively, this mechanism - which works differently under the two contractual arrangements - makes it less profitable the false revelation of the agent's private information. We summarize the foregoing argument with the following:

Proposition 2. When the high-demand type has an incentive to misreport, the low-demand type will face an output distortion under either contractual regime. This distortion will be negative as long as $\Delta \theta+\rho \Delta q_{2}(\theta)>0$.

For any model parameterization - in particular, for any degree of downstream market externalities - either contractual regime (QF versus RPM) is able to induce self-selection at equilibrium. Hence, the standard secondbest contract inducing fully separating allocations will be implementable, even when the retail price is not contracted upon. As we are going to show,

I3 The equilibrium allocation with RPM contracts is reported in Appendix F. 
this is no longer the case when the agency relationship features countervailing incentives, as the latter crucially alter the revelation strategies of the privately informed agent.

It is worth emphasizing that this neutrality result - i.e., the choice between complete or incomplete contracts has identical ex-post implications with respect to truthful information disclosure - rests on our assumption of costless design of each contractual mode. Complete contracts are generally known to be more costly to design and/or to enforce. Since our subsequent analysis suggests that the principal's interests are best served by offering incomplete contracts when countervailing incentives matter, considering costly design of (more) complete contracts would unambiguously strengthen our findings.

\section{CONTRACTING UNDER COUNTERVAILING INCENTIVES}

\subsection{Countervailing incentives}

This section studies the incidence of countervailing incentives (CI) on the revelation strategies of agents in order to obtain new intuitions on the optimal design of contractual arrangements. To this end, we slightly modify our basic framework of analysis to allow for type-specific outside opportunities. The assumption of identical (type-independent) reservation utilities, while greatly simplifying the analysis, often appears unrealistic. As pointed out, among others, by Jullien (200o), it is highly likely that an efficient agent (e.g., in terms of productivity or production costs) enjoys better outside opportunities than those faced by an inefficient one, both in the current relationship (or in a hypothetical continuation of the latter) and in alternative one ${ }^{14}$. As a consequence, informational rent may prove nonmonotonic over the type space (e.g., Jullien, 2000) ${ }^{15}$. We intro-

I4 See Laffont and Martimort (2002) for several economically significant instances of countervailing incentives models.

I5 In this respect, Jullien (2000) identifies three relevant economic contexts in which an agent's reservation utility is affected by his type: i) when two principals competing for signing an exclusive deal with an agent, the offer made by one of them 
duce type-dependent reservation utilities by positing the following participation constraints for $\theta \in \Theta$ :

$$
\begin{gathered}
P C(\underline{\theta}): \quad U(\underline{\theta}) \geq 0 \\
P C(\bar{\theta}): \quad U(\bar{\theta}) \geq U_{0}>0 \\
U_{0}>\left(\Delta \theta+\rho \Delta q_{2}(\theta)\right) q_{1}(\bar{\theta})^{C I}
\end{gathered}
$$

where the superscript $C I$ stands for countervailing incentives, and denotes the equilibrium allocation for the contractual problem under type-dependent outside opportunities. Formally, the latter restriction is imposed to ensure that misreporting incentives also arise for the low-demand type. As Laffont and Martimort (2002) argue, type-dependent participation constraints may alter the natural ordering of the incentive and participation constraints which characterizes the standard asymmetric information case. In particular, under a sufficiently high reservation utility for the $\bar{\theta}$-agent, participation of the latter in the contract may require better contractual terms which in turn become attractive for the low-demand type, who may now benefit from a strictly positive rent. As an example, consider the case where (screened) low-demand agents are precluded from participating into future relationships. If the gains from the possibility of future cooperation are sufficiently large, the low-demand agent may be induced to misreport his type to gain from repeated negotiations with the up-stream producer. In such a situation, (optimal) contract design is especially problematic as the set of incentive feasible contracts may be severely restricted: optimal contracting may require taking into account many non-trivial constraints, whose bearing may distort the second-best allocation further away from the first-best one (e.g., Jullien, 2000).

However, it is plausible to conjecture that a similar scenario generates also a countervailing effect on the high-demand type's revelation strategies as

determines the agent's outside opportunity in the negotiation process with the other; ii) when the principal requires the agent to implement transaction-specific investments, the ability of the latter to engage in an alternative relationship and his negotiation power can be significantly reduced; iii) when the parties can renegotiate the original agreement, the agent's reservation utility is conditioned by the level of utility granted by the original contract. 
the latter might want to voluntarily give up some of the information rent - which would result in the current relationship from misreporting - to take part into the continuation game and obtain a strictly positive payoff. The latter remark can be exploited for the optimal design of the incentive mechanism: if the gain from subsequent negotiations is sufficiently large to induce misreporting from the low-demand type, it should also counterbalance the high-demand type's incentive to untruthful revelation in the current relationship. Hence, the principal finds it not profitable to distort allocative efficiency with the aim of reducing the informational rent of the high-demand agent, which is bounded from below by his reservation utility, and conjectures that the relevant constraints for the contracting problem are represented by the high-demand agent's PC and the lowdemand one's IC constraint. We label this mechanism - under which only high-demand type's production level is distorted - as the simple CI-adjusted second-best contract (e.g., Laffont and Martimort, 2002).

We show that the actual effects of countervailing incentives on the equilibrium set crucially depend on the degree of contractual incompleteness. In particular, we establish that the use of QF contracts can always ensure self-selection under CI. In the presence of an RPM contractual regime, by contrast, the standard second-best contract adjusted for the presence of CI fails to be incentive-compatible under several parameterizations of the model; as a consequence, fully separating allocations - if existing - will be characterized by a larger distortion from the first-best ones.

\subsection{Comparison of the two structures}

\section{The vertically integrated structure.}

For any $\theta \in \Theta$ and pair $\left\{e(\theta) q_{1}(\theta)\right\}$, the optimization program is the same as in the case of standard distortion and then leads to the same reaction functions (4).

\section{The hierarchy.}

To show that the principal can exploit contractual incompleteness as a screening device in the presence of $\mathrm{CI}$, we follow the standard route of considering the PC of the high-demand type and the IC constraint of the lowdemand type as the only relevant constraints for the contractual problem. 
It will then be checked ex post, using the resulting allocation(s), that only QF contracts are able to ensure always - i.e., under any parameterization of the model - that the omitted constraints are satisfied.

\section{Ir. Quantity Fixing.}

It is straightforward to note that the first- and second-order conditions for the optimal level of effort are unaltered and coincide with (I2) and (I3). The auxiliary program of the principal can be written as follows (see Appendix D):

$$
\begin{gathered}
P_{1}: \max _{q_{1}} \frac{1}{2}\left[\left(\bar{\theta}+e(\bar{\theta})-q_{1}(\bar{\theta})+\rho q_{2}(\bar{\theta})\right) q_{1}(\bar{\theta})-\Psi(e(\bar{\theta}))-U_{0}\right]+ \\
\frac{1}{2}\left[\left(\underline{\theta}+e(\underline{\theta})-q_{1}(\underline{\theta})+\rho q_{2}(\underline{\theta})\right) q_{1}(\underline{\theta})-\Psi(e(\underline{\theta}))-\left(U_{0}-\left(\Delta \theta+\rho \Delta q_{2}(\theta)\right) q_{1}(\bar{\theta})\right)\right] .
\end{gathered}
$$

The reaction functions associated with the previous problem are given, for any $\theta \in \Theta$, by:

$$
q_{1}(\bar{\theta})=\frac{\left(\bar{\theta}+e(\bar{\theta})+\rho q_{2}(\bar{\theta})\right)}{2}+\frac{\left(\Delta \theta+\rho \Delta q_{2}(\theta)\right)}{2}
$$

and

$$
q_{1}(\underline{\theta})=\frac{\left(\underline{\theta}+e(\underline{\theta})+\rho q_{2}(\underline{\theta})\right)}{2} .
$$

\section{Resale Price Maintenance.}

The level of effort exerted by the agent is still obtained from the inverse demand function (I), and hence remains identical to that derived in the complete information case, as does the agent's expected utility. The auxiliary program of the principal is then (see Appendix D):

$$
\begin{aligned}
P_{1}^{R}: \max _{q_{1}(\cdot), e(\cdot)} & \frac{1}{2}\left[\left(\bar{\theta}+e(\bar{\theta})-q_{1}(\bar{\theta})+\rho q_{2}(\bar{\theta})\right) q_{1}(\bar{\theta})-\Psi(e(\bar{\theta}))-U_{0}\right]+ \\
& \frac{1}{2}\left[\left(\underline{\theta}+e(\underline{\theta})-q_{1}(\underline{\theta})+\rho q_{2}(\underline{\theta})\right) q_{1}(\underline{\theta})-\Psi(e(\underline{\theta}))-\right. \\
& \left.\left(U_{0}+\Psi(e(\bar{\theta}))-\Psi\left(e(\bar{\theta})+\left[\Delta \theta+\rho \Delta q_{2}(\theta)\right] q_{1}(\bar{\theta})\right)\right)\right],
\end{aligned}
$$


and for any $\theta \in \Theta$, the first-order conditions with respect to effort and quantity are:

$$
\begin{gathered}
q_{1}(\theta)=\frac{\theta+e(\theta)+\rho q_{2}(\theta)}{2}, \\
e(\bar{\theta})=\frac{q_{1}(\bar{\theta})}{\psi}+\frac{\left(\Delta \theta+\rho \Delta q_{2}(\theta)\right)}{\psi}
\end{gathered}
$$

and

$$
e(\underline{\theta})=\frac{q_{1}(\underline{\theta})}{\psi} .
$$

\subsection{Second-best allocations}

For the purpose of the analysis, let us assume for the moment that systems (23)-(24) and (26)-(28) fully characterize second-best equilibrium allocations under the QF and RPM regime, respectively ${ }^{16}$.

When no vertical price control exists (QF contract), the low-demand type agent is imposed the first-best production quantity while the quantity for the high-demand type proves distorted. This finding is perfectly in line with the contracting literature dealing with countervailing incentives (e.g., Laffont and Martimort, 2002), where an upward distortion for the efficient type is needed to squeeze the costly rent captured by the inefficient one.

Remarkably, this distortion involves an indirect effect on the actual level of effort of the high-demand type, which stems from an independent adjustment of the retailer to the requested allocation rather than from a direct contractual provision ${ }^{17}$.

I6 To this end, we should verify ex post that the omitted constraints from the auxiliary programs studied in the previous sections, i.e. those (assumed) not relevant for the contractual problem, are indeed not violated. This will be at the core of our analysis in the following section.

I7 The equilibrium allocation with QF contracts in the presence of CI is reported in Appendix G. 
As in the standard asymmetric information case, by exploiting RPM contracts the principal relies on the effort requirement rather than on quantity provisions to extract the informational rent. However, the presence of $\mathrm{CI}$ induces an effort distortion for the high-demand type, that indirectly brings about a shift (in the same direction) of the quantity required to the latter ${ }^{18}$.

We summarize the foregoing arguments in the following:

Proposition 3. Irrespective of the contractual arrangement in place ${ }^{\mathrm{I} 9}$, when the low-demand agent has an incentive to misreport his type, the high-demand type will face an output distortion under either contractual regime. This distortion will be positive as long as $\Delta \theta+\Delta \rho q_{2}(\theta)>0$.

\section{CONTRACTUAL INCOMPLETENESS AND SCREENING}

This section discusses the nexus between the degree of contractual completeness and the characterization of equilibria. To this end, we identify the precise circumstances under which a less binding arrangement such as the QF contract grants the principal efficiency gains - arising from its screening ability - which balance the loss incurred from relinquishing on an available monitoring tool.

The next propositions posit the main findings of our analysis:

Proposition 4. In the presence of standard distortion, $U(\theta) \geq U(\tilde{\theta} \mid \theta) \forall \tilde{\theta}, \theta \in \Theta$, irrespective of the elected contractual arrangement.

Proof. - See Appendix I.

I8 The equilibrium allocation with RPM contracts in the presence of CI is reported in Appendix $\mathrm{H}$.

I9 That is, irrespective of whether the principal exercises direct control on the quantity or rather (trough vertical price control) on the effort requirement. 
The interpretation of this result is straightforward. Under standard distortion, the low-demand type has no incentive to misrepresent his private information, as claiming to cope with a high level of demand, he would need to exert a level of effort which proves different from the optimal one and hence incur into excessive losses. This effect is further amplified when the distortion introduced by the principal generates an underproduction equilibrium result for the low-demand type. As a consequence, regardless of the contractual arrangement employed by the principal, truthful information disclosure represents an optimal strategy for the agent operating in a market characterized by a low realization of demand and no incentive mechanism for correct reporting is needed.

Proposition 5. In the presence of countervailing incentives, $U(\theta) \geq U(\tilde{\theta} \mid \theta) \forall \tilde{\theta}, \theta \in \Theta$ obtains:

- for any model's parameterization, with QF contracts;

- if and only if $\psi>\max \left\{\frac{1}{2}, \frac{\rho-4 \sigma \rho-2 \rho^{2}+2}{2(2+\rho)}\right\}$, with RPM contracts ${ }^{20}$.

Proof. - See Appendix L.

The incentive effect for the revelation strategies of agents is strongly influenced by the choice of the contractual regime. With QF contracts, the agent has no bounds on the level of effort to exert, given the quantity required in the contract. In this case, the distortion in the equilibrium quantity of the high-demand retailer has the same effect of the standard distortion introduced in the second best contract: when the gap between the production levels associated with the two possible states of nature changes, the informational rent enjoyed by the agent under false revelation is modified accordingly. In fact, when the retailer is left free to select the optimal level of effort, the gain from lowering the effort exertion are outweighed by the gain resulting from a more advantageous distribution of market shares. Since the agent is residual claimant of the outcome of the extra-production activities intended to increase the demand in the retail market, a strong incentive exists to exert a larger level of effort.

20 Given the assumed ranges for the involved parameters and the SOC (13), this restriction can hold true only when $\rho>0$ and $\sigma<-1 / 2$ or when $\rho<0$ and $\sigma>1 / 2$. 
In the case of RPM contracts, by contrast, the level of effort exercised by the agent is indirectly controlled by the principal and cannot be modified by the former. Under these circumstances, the revelation strategy of the highdemand type is ambiguous and truthful information disclosure obtains if and only if the net gain from exerting a higher level of effort outperforms the informational rent from misreporting; conversely, when the exertion of a lower level of effort allows a reduction of the associated disutility, false revelation can grant a higher profit that might counterbalance the potential loss arising from non-participation in the subsequent relationship(s). This condition in turn relies on the (private or cooperative) nature of the effort and the market relation between the competing goods.

Specifically, when $\rho$ and $\sigma$ have the same sign, the gains from a more profitable allocation of market shares exceed the costs from effort disutility, and truthful revelation occurs. Intuitively, when the goods are complement and the effort has a cooperative nature $(\rho>0$ and $\sigma>0)$ or when the goods are substitutes and the effort has a private nature $(\rho<0$ and $\sigma<0$ ), the (contractual) imposition of a higher level of effort positively affects downstream market competition, and hence does not prevent truthful revelation ${ }^{2 \mathrm{I}}$.

On the other hand, when $\rho$ and $\sigma$ have opposite sign, a higher level of effort adversely impacts the agents' reporting incentives. With complement goods $(\rho>0)$ and private effort $(\sigma<0)$, the effort-induced effect on market competition might fail to balance the increased effort disutility. This holds true, a fortiori, when goods are substitute and the effort has cooperative nature $(\rho<0, \sigma>0)$. In this case, by distorting the hightype effort choice in order to induce truthful revelation on the low-type's part, RPM arrangements dramatically alter the revelation strategies of the former, who might in fact benefit from misreporting.

In the standard asymmetric information environment with substitute goods $(\rho<0)$ and cooperative effort $(\sigma>0)$, the strategic effect of $\mathrm{QF}$

2I As shown in Martimort and Piccolo (20I0), QF contracts are more profitable for the principal than RPM ones. In fact, since products are differentiated and efforts generate demand spillovers, the strategic effect induced by the choice of a QF regime becomes increasingly relevant when market and effort externalities have the same sign. Hence, even when RPM arrangements can be used to separate different types of agents, the principal may still wish to exploit QF contracts to set up the hierarchical relationship. 
contracts generates a stronger market reaction from the competing structure as long as the consumers' willingness to pay increases due to the demand-enhancing effect of effort. Martimort and Piccolo (20I0) establish that, under these circumstances, the principal strictly prefers the RPM arrangement over the QF one. Our results show that, in the free-riding context $\sigma \rho<0$, the principal's interests might be best served by QF contracts when the disutility of effort is sufficiently high and countervailing incentives matter, as the latter ultimately influence the revelation strategies of privately informed retailers.

The following proposition summarizes our main finding:

Proposition 6. When $\frac{1}{2}<\psi \leq \frac{\rho-4 \sigma \rho-2 \rho^{2}+2}{2(2+\rho)}$, the simple CI-adjusted contract is not incentive-compatible.

When the agent's effort choices are (indirectly) determined by contractual provisions, retailers may prove unable to take advantage of the positive externalities prevailing in the downstream market, and hence choose to falsely report his type. As a consequence, (more) complete contracts may well fail to induce fully separating allocations, and hence impose further distortions from the first-best to satisfy incentive-compatibility, exacerbating the efficiency loss of the transaction.

This simple result can also be related to the notion of ratchet effect (e.g., Baron and Besanko, 1987; Laffont and Tirole, 1988). When defining his revelation strategies, the agent anticipates the possibility that the principal may use the information disclosed to design a new continuation equilibrium for the subsequent relationship(s); hence, a truthful revelation in the first period may nullify the informative advantage of the agent in all the possible following phases of the game. When no informative advantage in the second period is related to the agent's type, participation in the subsequent relationship(s) cannot compensate for the loss generated by the non-optimal level of effort exerted in the first one and, hence, untruthful disclosure can still configure a dominant strategy ${ }^{22}$.

22 A fortiori, the same consideration applies for the case of QF contracts. In this case, however, the agent is residual claimant of the benefits from the demand-enhancing activities, and hence can still obtain positive profits from all the relationships while not enjoying any informative advantage in the subsequent one(s). 


\section{CONCLUSION}

This paper analyzes the screening role of incomplete contracts in a simple producer-retailer economy characterized by asymmetric information. As a main result, it is shown that the design of the contractual arrangement has an inherent strategic value as ascreening device when countervailing incentives arise in vertical contracting. This finding emphasizes a novel aspect of the strategic value of quantity forcing contracts within competing vertical inter-firm relationships. As argued in Martimort and Piccolo (20Io), simple contracts are widespread business practice in these environments, as they often involve delegation of marketing activities to retailers, or lack restricting clauses that would endow manufacturers with forceful tools of vertical control within the agency relationship. These authors show that less complete arrangements may be more profitable when some aspects of the agents' activity are non-contractible. We complement this finding by establishing that, when countervailing incentives play a role in the underlying agency relationship, the choice of the contractual regime also matters for the nature of the underlying equilibrium outcome.

Vertical contracts based on retail price control are well-understood as useful devices to handle information free-riding by retailers or to help deal with double-marginalization issues. As a policy implication, our analysis rather suggests some caution on the employment of such type of arrangements within complex industry relationships which may be plagued by countervailing incentives issue (e.g., Jullien, 2000). Whilst framed in a stylized manufacturer-retailer model economy, this result might support the use of simpler contracts in more complex environments characterized by vertical (contractual) and horizontal externalities (e.g., procurement contracting).

The model is written in the simplest form that still conveys the key message. A twofold robustness check for our findings would require extending the analysis of incomplete contracting to the continuous-type case and to the possibility of renegotiation. In fact, as argued in Hermalin and Katz (1993), literally incomplete contracts may have no effects when they are not renegotiation-proof. Also, the scope for repeated negotiations and its impact on the strategic value of contractual incompleteness should be thoroughly examined. Apparently, any strategic advantage of incomplete 
over complete agreements will rely on the interplay between the basic ingredients of the dynamic model, i.e. type correlation, the magnitude of the discount rate and the possibility of renegotiation. We leave this and other related issues to future research.

\section{APPENDIX}

\section{Appendix A: Derivation of the IC constraints with QF contracts}

Given the agent's utility function (6), the IC constraint is:

$$
\begin{aligned}
I C(\theta): & {\left[\left(\theta+e(\theta)-q_{1}(\theta)+\rho q_{2}(\theta)\right) q_{1}(\theta)-\Psi(e(\theta))-t(\theta)\right] } \\
\geq & {\left[\left(\theta+e(\tilde{\theta})-q_{1}(\tilde{\theta})+\rho q_{2}(\theta)\right) q_{1}(\tilde{\theta})-\Psi(e(\tilde{\theta}))-t(\tilde{\theta})\right], }
\end{aligned}
$$

where $\theta$ represents the actual realization of demand and $\tilde{\theta}$ denotes the false agent's report. Hence, the high-demand agent's IC constraint is:

$$
\begin{aligned}
I C(\bar{\theta}) & :\left[\left(\bar{\theta}+e(\bar{\theta})-q_{1}(\bar{\theta})+\rho q_{2}(\bar{\theta})\right) q_{1}(\bar{\theta})-\Psi(e(\bar{\theta}))-t(\bar{\theta})\right] \\
\geq & {\left[\left(\bar{\theta}+e(\underline{\theta})-q_{1}(\underline{\theta})+\rho q_{2}(\bar{\theta})\right) q_{1}(\underline{\theta})-\Psi(e(\underline{\theta}))-t(\underline{\theta})\right] . }
\end{aligned}
$$

The left-hand side is the utility from truthful type revelation. The righthand side can be rewritten as a function of the low-demand agent's utility and of a term capturing the scope and impact of the asymmetric distribution of information, i.e.:

$$
U_{1}^{Q}(\bar{\theta}) \geq U^{Q}(\underline{\theta})+\left(\Delta \theta+\rho \Delta q_{2}(\theta)\right) q_{1}(\underline{\theta}) .
$$

It must be emphasized that the term $\Delta \theta+\rho \Delta q_{2}(\theta)$ captures two distinct features of the model: first, the standard information rent, that the $\bar{\theta}$-agent benefits from thanks to his ability to possibly mimic the lowdemand type; second, the information rent which stems from the competitive environment in which the retailer operates, and represented by the differences in the competitor's production levels with respect to the different states of natures $\theta \in \Theta$. Remarkably, even when the contract entails a non-zero quantity for the low-demand type, i.e. $q_{1}(\underline{\theta})>0$, the overall term capturing the information rent problem need not be strictly positive for any parameterization of the model. 
Similarly, the low-demand agent's IC constraint is:

$$
U^{Q}(\underline{\theta}) \geq U^{Q}(\bar{\theta})-\left(\Delta \theta+\rho \Delta q_{2}(\theta)\right) q_{1}(\bar{\theta}) .
$$

14. Appendix B: Derivation of the IC constraints with RPM contracts The generic formulation of the IC constraint is:

$$
\begin{gathered}
I C(\theta): p_{1}(\theta) q_{1}(\theta)-\Psi\left(p_{1}(\theta)+q_{1}(\theta)-\rho q_{2}(\theta)-\theta\right)-t(\theta) \\
\geq p_{1}(\tilde{\theta}) q_{1}(\tilde{\theta})-\Psi\left(p_{1}(\tilde{\theta})+q_{1}(\tilde{\theta})-\rho q_{2}(\theta)-\theta\right)-t(\tilde{\theta}) .
\end{gathered}
$$

The high-demand agent's IC can be written as:

or

$$
\begin{array}{r}
I C(\bar{\theta}): p_{1}(\bar{\theta}) q_{1}(\bar{\theta})-\Psi\left(p_{1}(\bar{\theta})+q_{1}(\bar{\theta})-\rho q_{2}(\bar{\theta})-\bar{\theta}\right)-t(\bar{\theta}) \\
\geq p_{1}(\underline{\theta}) q_{1}(\underline{\theta})-\Psi\left(p_{1}(\underline{\theta})+q_{1}(\underline{\theta})-\rho q_{2}(\bar{\theta})-\bar{\theta}\right)-t(\underline{\theta}),
\end{array}
$$

$$
U^{R}(\bar{\theta}) \geq U^{R}(\underline{\theta})+\Psi(e(\underline{\theta}))-\Psi\left(e(\underline{\theta})-\left(\Delta \theta+\rho \Delta q_{2}(\underline{\theta})\right) .\right.
$$

Similarly, the low-demand agent's IC constraint is:

$$
U^{R}(\underline{\theta}) \geq U^{R}(\bar{\theta})+\Psi(e(\bar{\theta}))-\Psi\left(e(\bar{\theta})+\left(\Delta \theta+\rho \Delta q_{2}(\theta)\right)\right.
$$

\section{I5. Appendix C: Derivation of the principal's program with QF contracts}

Using (6) and considering the two possible realizations of demand, the principal's constrained optimization program is

$$
\begin{aligned}
P_{1}^{Q}: \max _{q_{1}(\cdot)} \frac{1}{2}\left[\left(\bar{\theta}+e(\bar{\theta})-q_{1}(\bar{\theta})+\rho q_{2}(\bar{\theta})\right) q_{1}(\bar{\theta})-\Psi(e(\bar{\theta}))-U(\bar{\theta})\right]+ \\
\quad \frac{1}{2}\left[\left(\underline{\theta}+e(\underline{\theta})-q_{1}(\underline{\theta})+\rho q_{2}(\underline{\theta})\right) q_{1}(\underline{\theta})-\Psi(e(\underline{\theta}))-U(\underline{\theta})\right] \\
\text { s.t. } P C(\bar{\theta}), P C(\underline{\theta}), I C(\bar{\theta}), I C(\underline{\theta}) .
\end{aligned}
$$

The auxiliary program under standard distortion ( 9 ) is obtained by inserting the high-demand agent's informational rent (28) and assuming that the low-demand agent receives a null rent. By the same token, the auxiliary program under CI (2I) is obtained by using the low-demand type's informational rent (30) - with $U^{Q}(\bar{\theta}) \geq U_{0}$ - and letting the high-demand agent have a null rent. 
16. Appendix D: Derivation of the principal's program with RPM contracts

Using (13), the principal's program is given by:

$$
\begin{aligned}
P_{1}^{R}: \max _{q_{1}(\cdot), e(\cdot)} \frac{1}{2}\left[\left(\bar{\theta}+e(\bar{\theta})-q_{1}(\bar{\theta})+\rho q_{2}(\bar{\theta})\right) q_{1}(\bar{\theta})-\Psi(e(\bar{\theta}))-U(\bar{\theta})\right]+ \\
\quad \frac{1}{2}\left[\left(\underline{\theta}+e(\underline{\theta})-q_{1}(\underline{\theta})+\rho q_{2}(\underline{\theta})\right) q_{1}(\underline{\theta})-\Psi(e(\underline{\theta}))-U(\underline{\theta})\right] \\
\text { s.t. } P C(\bar{\theta}), P C(\underline{\theta}), I C(\bar{\theta}), I C(\underline{\theta}) .
\end{aligned}
$$

Substituting (3I) into this generic formulation program and assuming away the informational rent of the low-demand agent, one obtains the principal's program in the case of standard distortion (I6), while the analogous under CI (24) is obtained using (32) and assuming that the the highdemand agent's rent is represented by his reservation utility $\left(U_{0}>0\right)$.

\section{Appendix E: Equilibrium with QF contracts and standard distortion}

The second best allocation, expressed as a function of the first best one, is obtained using the reaction functions of the integrated structure (4) and those of the hierarchical relationship (Iо) and (II), as well as the firstorder condition with respect to effort $(7)^{23}$.

$$
\begin{aligned}
& q_{1}^{S B}(\bar{\theta})=q_{1}^{F B}(\bar{\theta}), \\
& q_{1}^{S B}(\underline{\theta})=q_{1}^{F B}(\underline{\theta})-\frac{2 \Delta(2+\rho)(1-2 \psi) \psi}{\left(4 \psi-\psi \rho^{2}-\rho \sigma-2\right)\left(\rho \sigma-2 \psi+\psi \rho^{2}+1\right)}, \\
& e^{S B}(\bar{\theta})=e^{F B}(\bar{\theta}), \\
& e^{S B}(\underline{\theta})=e^{F B}(\underline{\theta})-\frac{2 \Delta(2+\rho)(1-2 \psi)}{\left(4 \psi-\psi \rho^{2}-\rho \sigma-2\right)\left(\rho \sigma-2 \psi+\psi \rho^{2}+1\right)}, \\
& q_{2}^{S B}(\bar{\theta})=q_{2}^{F B}(\bar{\theta}), \\
& q_{2}^{S B}(\underline{\theta})=q_{2}^{F B}(\underline{\theta})-\frac{\Delta(\sigma+\psi \rho)(2+\rho)(1-2 \psi)}{\left(4 \psi-\psi \rho^{2}-\rho \sigma-2\right)\left(\rho \sigma-2 \psi+\psi \rho^{2}+1\right)} .
\end{aligned}
$$

23 To isolate the effects of information asymmetries, the possible realizations of $\theta$ are centered around 1 , i.e. $\bar{\theta}=1+\Delta$ and $\underline{\theta}=1-\Delta$, assuming $\Delta=\Delta \theta / 2<1$. 
Notice that:

$$
\left(\Delta \theta+\rho \Delta q_{2}(\theta)\right)=\frac{(2 \psi-1)(\rho+2) \Delta}{\left(2 \psi-\sigma \rho-\psi \rho^{2}-1\right)}>0 \Leftrightarrow\left(2 \psi-\sigma \rho-\psi \rho^{2}-1\right)>0,
$$

and

$$
q_{1}(\bar{\theta})-q_{1}(\underline{\theta})=\frac{2(\rho+2) \Delta \psi}{\left(2 \psi-\sigma \rho-\psi \rho^{2}-1\right)}>0 \Leftrightarrow\left(2 \psi-\sigma \rho-\psi \rho^{2}-1\right)>0 .
$$

This proves Lemma in the main text.

18. Appendix F: Equilibrium with RPM contracts and standard distortion Equilibrium effort and quantity with RPM contracts, obtained using (4) and (17)-(20), are given by:

$$
\begin{gathered}
q_{1}^{S B}(\bar{\theta})=q_{1}^{F B}(\bar{\theta}), \\
q_{1}^{S B}(\underline{\theta})=q_{1}^{F B}(\underline{\theta})-\frac{2 \Delta(2+\rho \sigma)(2+\rho)(1-2 \psi)}{\left(4 \psi-\psi \rho^{2}-\rho \sigma-2\right)\left(3 \sigma \rho-4 \psi+\rho^{2}+\psi \rho^{2}+2\right)}, \\
e^{S B}(\bar{\theta})=e^{F B}(\bar{\theta}), \\
e^{S B}(\underline{\theta})=e^{F B}(\underline{\theta})-\frac{2 \Delta(1-2 \psi)(2+\rho)^{2}(2-\rho)}{\left(4 \psi-\psi \rho^{2}-\rho \sigma-2\right)\left(3 \sigma \rho-4 \psi+\rho^{2}+\psi \rho^{2}+2\right)} \\
q_{2}^{S B}(\underline{\theta})=q_{2}^{F B}(\underline{\theta})-\frac{q_{2}^{S B}(\bar{\theta})=q_{2}^{F B}(\bar{\theta}),}{\left(4 \psi-\psi \rho^{2}-\rho \sigma-2\right)\left(3 \sigma \rho-4 \psi+\rho^{2}+\psi \rho^{2}+2\right)} .
\end{gathered}
$$

\section{Appendix G: Equilibrium with QF contracts and CI}

Equilibrium effort and quantity are obtained by using the reaction functions of the two competitors (4), (22) and (23) and the first order condition with respect to effort (7):

$$
\begin{gathered}
q_{1}^{C I}(\bar{\theta})=q_{1}^{F B}(\bar{\theta})+\frac{2 \Delta(2+\rho)(1-2 \psi) \psi}{\left(4 \psi-\psi \rho^{2}-\rho \sigma-2\right)\left(\sigma \rho-2 \psi+\psi \rho^{2}+1\right)}, \\
q_{1}^{C I}(\underline{\theta})=q_{1}^{F B}(\underline{\theta}),
\end{gathered}
$$




$$
\begin{gathered}
e^{C I}(\bar{\theta})=e^{F B}(\bar{\theta})+\frac{2 \Delta(2+\rho)(1-2 \psi)}{\left(4 \psi-\psi \rho^{2}-\rho \sigma-2\right)\left(\sigma \rho-2 \psi+\psi \rho^{2}+1\right)}, \\
e^{C I}(\underline{\theta})=e^{F B}(\underline{\theta}), \\
q_{2}^{C I}(\bar{\theta})=q_{2}^{F B}(\bar{\theta})+\frac{\Delta(\sigma+\psi \rho)(2+\rho)(1-2 \psi)}{\left(4 \psi-\psi \rho^{2}-\rho \sigma-2\right)\left(\sigma \rho-2 \psi+\psi \rho^{2}+1\right)}, \\
q_{2}^{C I}(\underline{\theta})=q_{2}^{F B}(\underline{\theta}) .
\end{gathered}
$$

\section{Appendix H: Equilibrium with RPM contracts and CI}

The equilibrium allocation is derived from the reaction functions of the two competitors $(4),(25)-(27)$ :

$$
\begin{gathered}
q_{1}^{C I}(\bar{\theta})=q_{1}^{F B}(\bar{\theta})+\frac{2 \Delta\left(2 \sigma \rho-\rho-4 \psi+2 \psi \rho+2 \psi \rho^{2}+2\right)(2+\rho \sigma)}{\left(4 \psi-\psi \rho^{2}-\rho \sigma-2\right)\left(\psi \rho^{2}-\sigma \rho-\rho^{2}-4 \psi+2\right)}, \\
q_{1}^{C I}(\underline{\theta})=q_{1}^{F B}(\underline{\theta}), \\
e^{C I}(\bar{\theta})=e^{F B}(\bar{\theta})+\frac{2 \Delta\left(2 \sigma \rho-\rho-4 \psi+2 \psi \rho+2 \psi \rho^{2}+2\right)(2+\rho)(2-\rho)}{\left(4 \psi-\psi \rho^{2}-\rho \sigma-2\right)\left(\psi \rho^{2}-\sigma \rho-\rho^{2}-4 \psi+2\right)}, \\
e^{C I}(\underline{\theta})=e^{F B}(\underline{\theta}), \\
q_{2}^{C I}(\bar{\theta})=q_{2}^{F B}(\bar{\theta})+\frac{2 \Delta\left(2 \sigma \rho-\rho-4 \psi+2 \psi \rho+2 \psi \rho^{2}+2\right)(2 \sigma+\rho)}{\left(4 \psi-\psi \rho^{2}-\rho \sigma-2\right)\left(\psi \rho^{2}-\sigma \rho-\rho^{2}-4 \psi+2\right)} \\
q_{2}^{C I}(\underline{\theta})=q_{2}^{F B}(\underline{\theta}) .
\end{gathered}
$$

\section{I. Appendix I: Proof of Proposition 4}

Under standard distortion, the principal takes into account the highdemand agent's IC constraint when designing the contract and verifies ex post that the low-demand agent's IC constraint is not violated. The latter is given by:

$$
q_{1}(\underline{\theta})\left(\Delta \theta+\rho \Delta q_{2}(\theta)\right)-q_{1}(\bar{\theta})\left(\Delta \theta+\rho \Delta q_{2}(\theta)\right) \leq 0 .
$$

or equivalently, using the equilibrium level of effort and quantity: 


$$
\frac{2 \psi(2 \psi-1)(\rho+2)^{2} \Delta^{2}}{\left(\sigma \rho-2 \psi+\psi \rho^{2}+1\right)^{2}} \geq 0,
$$

which is always satisfied given the assertion of Lemma $\mathrm{I}$.

With RPM contracts, the IC constraint for the low-demand agent is:

$$
\Psi(e(\underline{\theta}))-\Psi\left(e(\underline{\theta})-\left(\Delta \theta+\rho \Delta q_{2}(\theta)\right)\right)+\Psi(e(\bar{\theta}))-\Psi\left(e(\bar{\theta})+\left(\Delta \theta+\rho \Delta q_{2}(\theta)\right)\right) \leq 0,
$$

or equivalently, using the equilibrium level of effort and quantity:

$$
\frac{8 \psi(2 \psi-1)(\psi+1)(\rho+2)^{2} \Delta^{2}}{\left(3 \sigma \rho-4 \psi+\rho^{2}+\psi \rho^{2}+2\right)^{2}} \geq 0 .
$$

The latter is always satisfied given (8).

\section{Appendix L: Proof of Proposition 5}

In the case of CI, the principal takes into account the low-demand agent's IC constraint when designing the contract and verifies ex post that the high-demand agent's IC constraint is not violated.

With QF contracts, the latter is given by:

$$
q_{1}(\underline{\theta})\left(\Delta \theta+\rho \Delta q_{2}(\theta)\right)-q_{1}(\bar{\theta})\left(\Delta \theta+\rho \Delta q_{2}(\theta)\right) \leq 0,
$$

and using the equilibrium quantities (45), (46), (49) and ( 50$)$ :

$$
\frac{2 \psi(2 \psi-1)(\rho+2)^{2} \Delta^{2}}{\left(\sigma \rho-2 \psi+\psi \rho^{2}+1\right)^{2}} \geq 0,
$$

which always holds true given (8).

With RPM contracts, the high-demand type's IC constraints is:

$$
\Psi(e(\bar{\theta}))-\Psi\left(e(\bar{\theta})+\left(\Delta \theta+\rho \Delta q_{2}(\theta)\right)\right)+\Psi(e(\underline{\theta}))-\Psi\left(e(\underline{\theta})-\left(\Delta \theta+\rho \Delta q_{2}(\theta)\right)\right) \leq 0,
$$

and using the equilibrium level of effort and quantity for the vertically integrated structure, (53) and (56), it can be written as: 


$$
\frac{8 \psi\left(4 \psi-\rho+4 \sigma \rho+2 \psi \rho+2 \rho^{2}-2\right)(2 \psi-\rho+2 \sigma \rho+\psi \rho+2) \Delta^{2}}{\left(4 \psi+\sigma \rho+\rho^{2}-\psi \rho^{2}-2\right)^{2}} \geq 0,
$$

the latter being satisfied if:

$$
\psi>\max \left\{\frac{1}{2}, \frac{\rho-4 \rho \sigma-2 \rho^{2}+2}{2(2+\rho)}, \frac{\rho-2 \rho \sigma-2}{2+\rho}\right\},
$$

or if:

$$
\frac{1}{2}<\psi<\min \left\{\frac{\rho-4 \sigma \rho-2 \rho^{2}+2}{2(2+\rho)}, \frac{\rho-2 \sigma \rho-2}{2+\rho}\right\} .
$$

Since $\frac{\rho-4 \sigma \rho-2 \rho^{2}+2}{2(2+\rho)}>\frac{\rho-2 \sigma \rho-2}{2+\rho}$ and $\frac{\rho-2 \sigma \rho-2}{2+\rho}<\frac{1}{2}$ for any $|\rho| \leq 1$ and $|\sigma| \leq 1$, the high-demand agent's IC constraint is not violated if and only if:

$$
\psi>\max \left\{\frac{1}{2}, \frac{\rho-4 \sigma \rho-2 \rho^{2}+2}{2(2+\rho)}\right\} .
$$

\section{REFERENCES}

ACCONCIA, A., MARTINA, E. ET PICCOLO, S. (2008), "Vertical Restraints under Asymmetric Information: On the Role of Participation Constraints ", Journal of Industrial Economics, vol. 56, pp. 379-40I.

ALLEN, F. ET GALE, D. (1992), " Measurement Distortion and Missing Contingencies in Optimal Contracts ", Economic Theory, vol. 2, pp. I-26.

ANDERLINI, L. Er FELLI, L. (1994), " Incomplete Written Contracts: Undescribable States of Nature ", Quarterly Journal of Economics, vol. I09, pp. I085-II24.

BARON, D. Er BESANKO, D. (I984), "Regulation and Information in a Continuing Relationship ", Information Economics and Policy, vol. I, pp. 267-302.

BARON, D. ET BESANKO, D. (1987), "Commitment and Fairness in a Dynamic Regulatory Relationship ", Review of Economic Studies, vol. 44, pp. 413-436.

BATTIGALli, P. Er MAGGI, G. (2002) "Rigidity, Discretion, and the Costs of Writing Contracts ", American Economic Review, vol. 92, pp. 798-817.

BERNHEIM, B.D. Er WHINSTON, M.D. (I998), "Incomplete Contracts and Strategic Ambiguity ", American Economic Review, vol. 88, pp. 902-932. 
CAILlAUD, B. ET HERMALIN, B.E. (2000), « Hidden-Information Agency », Unpublished manuscript.

CHE, Y.-K. (2000), " Can a Contract Solve Hold-Up when Investments have Externalities? A Comment on De Fraja (1999) ", Games and Economic Behavior, vol. 33, pp. 195-205.

CHE, Y.-K. \& HAUSCH, S. (I999), " Cooperative Investments and the Value of Contracting », American Economic Review, vol. 89, pp. I25-I47.

CHEVALIER, J.A., KASHYAP, A.K. ET ROSSI, P.E. (2003), "Why Don't Prices Rise During Periods of Peak Demand? Evidence from Scanner Data », American Economic Review, vol. 93, pp. I5-37.

DE FRAJA, G. (1999), "After you Sir. Hold-Up, Direct Externalities, and Sequential Investment ", Games and Economic Behavior, vol. 26, pp. 22-39.

DESSİ, R. (2007), "Contractual Enforcement and Strategic Incompleteness ", IDEI Working Paper No. 465 .

DEWATRIPONT, M. E MASKIN, E. (I990), "Contract Renegotiation in Models of Asymmetric Information ", European Economic Review, vol. 34, pp. 3II-32I.

DEWATRIPONT, M. ET MASKIN, E. (I995), « Contractual Contingencies and Renegotiation », RAND Journal of Economics, vol. 26, pp. 704-719.

FARES, M. (2006), "Renegotiation Design and Contractual Solutions to the Hold-Up Problem », Journal of Economic Surveys, vol. 20, pp. 73I-756.

FUDENBERG, D. E TIROLE, J. (I99I), " Game Theory », MIT Press, Cambridge, MA.

GAL-OR, E. (I99I), "Vertical Restraints with Incomplete Information », Journal of Industrial Economics, vol. 39, pp. 503-516.

GROSSMAN, S. ET HART, 0. (I986), "The Costs and Benefits of Ownership: A Theory of Vertical and Lateral Integration ", Journal of Political Economy, vol. 94, pp. 69I-7I9.

HART, O. E MOORE, J. (I990), "Property Rights and the Nature of the Firm », Journal of Political Economy, vol. 98, pp. III9-II58.

HART, O. ET MOORE, J. (I999), "Foundations of Incomplete Contracts ", Review of Economic Studies, vol. 66, pp. II5-гі8.

HERMALIN, B.E. ET KATZ, M.L. (I993), " Judicial Modification of Contracts between Sophisticated Parties: A More Complete View of Incomplete Contracts and Their Breach ", Journal of Law, Economics and Organization, vol. 9, pp. 230-255.

HOLMSTROM, B. (I982), " On the Theory of Delegation ", Unpublished manuscript.

HOLMSTROM, B. ET MILGROM, P.R. (I992), "Multitask Principal-Agent Analyses: Incentive Contracts, Asset Ownership, and Job Design », Journal of Law, Economics and Organization, vol. 7, 24-52.

JUlliEN, B (2000), "Participation Constraints in Adverse Selection Models ", Journal of Economic Theory, vol. 93, pp. I-47.

KASTL, J., MARTIMORT, D. Er PICCOLO, S. (20II), "When Should Manufacturers Want Fair Trade?: New Insights from Asymmetric Information when Supply Chains Compete ", Journal of Economics et Management Strategy, vol. 20, pp. 649-677.

LAFONTAINE, F. ET SLADE, M.E. (I997), "Retail Contracting: Theory and Practice", Journal of Industrial Economics, vol. 45, pp. I-25.

LAFONTAINE, F. ET SLADE, M.E. (20Io), "Transaction Cost Economics and Vertical Market Restrictions - Evidence ", The Antitrust Bulletin, vol. 55, pp. 587-6II.

LAFFONT, J.J. \& MARTIMORT, D. (2002), The Theory of Incentives: The Principal-Agent Model. Princeton University Press. 
LAFFONT, J.J. \& TIROLE, J. (I986), « Using Cost Observation to Regulate Firms », Journal of Political Economy, vol. 94, pp. 6r4-64I.

LAFFONT, J.J. E TIROLE J. (I988), "The Dynamics of Incentive Contracts ", Econometrica, vol. 56, pp. II53-II75.

LEWIS, T. ET SAPPINGTON, D.E.M. (I989), "Countervailing Incentives in Agency Problems ", Journal of Economic Theory, vol. 49, pp. 294-313.

MAGGI, G. ET RODRİGUEZ-CLARE A. (1995), " On Countervailing Incentives ", Journal of Economic Theory, vol. 66, pp. 238-263.

MARTIMORT, D. (I996), "Exclusive Dealing, Common Agency, and Multiprincipals Incentive Theory ", RAND Journal of Economics, vol. 27, pp. I-3I.

MARTIMORT, D. Er PICCOLO, S. (2007), "Resale Price Maintenance under Asymmetric Information ", International Journal of Industrial Organization, vol. 25, pp. 315-339.

MARTIMORT, D. ET PICCOLO, S. (20I0), "The Strategic Value of Quantity Forcing Contracts ", American Economic Journal: Microeconomics, vol. 2, pp. 204-229.

MASKIN, E. ET TIROLE, J. (I999), " Unforeseen Contingencies and Incomplete Contracts ", Review of Economic Studies, vol. 66, pp. 83-II4.

REY, P. ET TIROLE, J. (I986), "The Logic of Vertical Restraints ", American Economic Review, vol. 76, pp. 92I-939.

SEGAL, I. \& WHINSTON, M. (2002), " The Mirrlees Approach to Mechanism Design with Renegotiation (with Applications to Hold-Up and Risk Sharing) ", Econometrica, vol. 70 , pp. I-45.

SPENGLER, J. (I950), "Vertical Integration and Antitrust Policy ", Journal of Political Economy, vol. 63, pp. 347-52.

SPIER, K. (I992), "Incomplete Contracts and Signaling ", RAND Journal of Economics, vol. 23, pp. 432-443.

TELSER, L.G. (I960), "Why Should Manufacturers Want Fair Trade? ", Journal of Law and Economics, vol. 3, pp. 86-Io5.

TIROLE, J. (2009), "Cognition and Incomplete Contracts", American Economic Review, vol. 99, pp. 265-294.

WILLIAMSON, O. (1975), Markets and Hierarchies, Analysis and Antitrust Implications: A Study in the Economics of Internal Organization, New York, Free Press. 